\title{
ELEGTRICAL BEHAVIOUR OF FINELY DIVIDED ICE
}

\author{
By J. G. PAREN* \\ (British Antarctic Survey, Madingley Road, Cambridge $\mathrm{CB}_{3}$ oET, England) \\ and J. W. GLEN \\ (Department of Physics, University of Birmingham, Birmingham B I $_{5}$ 2TT, England)
}

\begin{abstract}
Aвstract. The electrical behaviour of ice which has been finely ground and compressed was investigated during ageing in air and over a range of temperatures. The dielectric behaviour may be accurately represented as the sum of two elliptical relaxation spectra. The behaviour eventually stabilizes with similar activation energies for the mean relaxation time of each spectrum $c .0 .25 \mathrm{eV}$, and the ratio of the relaxation times is ten in samples of density c. $0.4^{2} \mathrm{Mg} \mathrm{m}^{-3}$. Arguments are presented on whether the higher-frequency dispersion is a consequence of the heterogeneous nature of the samples or is a bulk relaxation process. The similarities between the behaviour of such finely ground ice and of deposited snow and polar glacier ice are discussed. The extent to which the results may be attributed to surface adsorption of $\mathrm{CO}_{2}$ are examined by reference to measurements of the $\mathrm{CO}_{2}$ content of finely divided ice and ice from polar regions.
\end{abstract}

RÉsumÉ. Comportement électrique de la glace finement divisée. Le comportement électrique de la glace finement divisée puis comprimée a été étudié pendant son vieillissement à l'air et dans un large domaine de température. Le comportement diélectrique peut être représenté de façon précise par la somme de deux spectres de relaxation. On observe une stabilisation du matériau avec des valeurs de l'énergie d'activation du temps de relaxation moyen, identiques pour les deux spectres $\approx 0,25 \mathrm{eV}$; le rapport entre les temps de relaxation est Io pour des échantillons de densité $\approx 0,42$. Nous présentons les arguments en faveur soit de l'hypothèse d'après laquelle la dispersion observée à plus haute fréquence est la conséquence de la nature hétérogène des échantillons, soit de l'hypothèse d'un processus de relaxation en volume. Les analogies entre le comportement d'une telle glace finement divisée et la neige transformée ou la glace de glaciers polaires sont discutées. L'idée suivant laquelle les résultats pourraient être attribués à l'adsorption en surface du $\mathrm{CO}_{2}$, est examinée en faisant référence aux mesures de teneur en $\mathrm{CO}_{2}$ dans la glace finement divisée ou dans la glace des régions polaires.

Zusammenfassung. Elektrisches Verhalten von fein verteiltem Eis. Das elektrische Verhalten von fein zerriebenem und danach zusammengepresstem Eis wurde während der Alterung in Luft und für mehrere Temperaturen untersucht. Das dielektrische Verhalten kann exakt als Summe von zwei elliptischen Relaxationsspektren dargestellt werden. Es erreicht schliesslich einen Zustand mit annähernd gleichen Aktivierungsenergien von $\approx 0,25 \mathrm{eV}$ für die mittlere Relaxationszeit eines jeden Spektrums, und das Verhältnis der Relaxationszeiten ist $10: \mathrm{I}$ in Proben der Dichte von $\approx 0,42 \mathrm{Mg} \mathrm{m} \mathrm{m}^{-3}$. Es wird erörtet, ob die Dispersion bei höheren Frequenzen eine Folge der uneinheitlichen Beschaffenheit der Proben ist, oder ob es sich um einen Volumenrelaxationsprozess handelt. Die Ähnlichkeit zwischen dem Verhalten derartig fein zerriebenen Eises, abgelagertem Schnee und Polargletschereis werden besprochen. Inwieweit die Ergebnisse der Oberflächenadsorption von $\mathrm{CO}_{2}$ zugeordnet werden können, wird unter bezug auf Messungen des $\mathrm{CO}_{2}$-Gehaltes fein verteilten Eises und Eises aus Polargebieten geprüft.

\section{INTRODUCTION}

A review by Glen and Paren (1975) on the electrical properties of snow and ice emphasized a lack of knowledge of the dominant relaxation spectrum in snow. Only Fujino (1967) had measured the temperature dependence of its relaxation frequency on one snow block of density $0.3^{8} \mathrm{Mg} \mathrm{m}^{-3}$ which he subsequently used as a matrix for a synthetic granular sea-ice sample made by soaking the block with brine at the freezing point. Fujino found that the granular sea ice also contained a dispersion with the same relaxation frequency as found in the snow and this suggests that the relaxation frequency in snow is inherent to the ice component. Nevertheless, the relaxation frequencies found by Fujino were much higher than in pure single crystals of ice (as other experiments have also shown) and had an activation energy of $0.27 \mathrm{eV}$.

We wished to investigate this result further by preparing a "snow" of finely divided ice made by shaving on a cheese grater in air at $-7^{\circ} \mathrm{C}$ large samples of ice whose dielectric behaviour we had also measured. The ice samples were cylindrical with diameter $c$. I $00 \mathrm{~mm}$ and exceeding $0.20 \mathrm{~m}$ in length. The grating was carried out on the plane end of the sample,

* Formerly at Department of Physics, University of Birmingham, Birmingham B ${ }_{5}$ 2TT, England. 
thereby providing shavings from the complete cross-section. Pure single crystals of ice and ice from I 424 m depth from "Byrd" station, Antarctica, were chosen for their contrasting bulk behaviour. The single crystal of ice (MPI provided by Dr S. J. Jones of Environment, Ottawa, Canada) behaved in bulk in general accord with published measurements. One dominant Debye dispersion was observed which had an activation energy for the relaxation time of $0.55 \mathrm{eV}$, and the implied d.c. conductivity obtained from an analysis of the a.c. response was $\mathrm{I} \times \mathrm{IO}^{-8} \Omega^{-\mathrm{I}} \mathrm{m}^{-\mathrm{I}}$ at $-10^{\circ} \mathrm{C}$. The "Byrd" station ice (as elaborated in the text and Figures 3, 4, 6, and 7) behaved differently and certain aspects of this have been identified before in studies on other bulk polar ice samples. The "snows" were then compressed in a dielectric cell with guard ring to a density between $0.3^{8}$ and $0.44 \mathrm{Mg} \mathrm{m}^{-3}$ to make direct

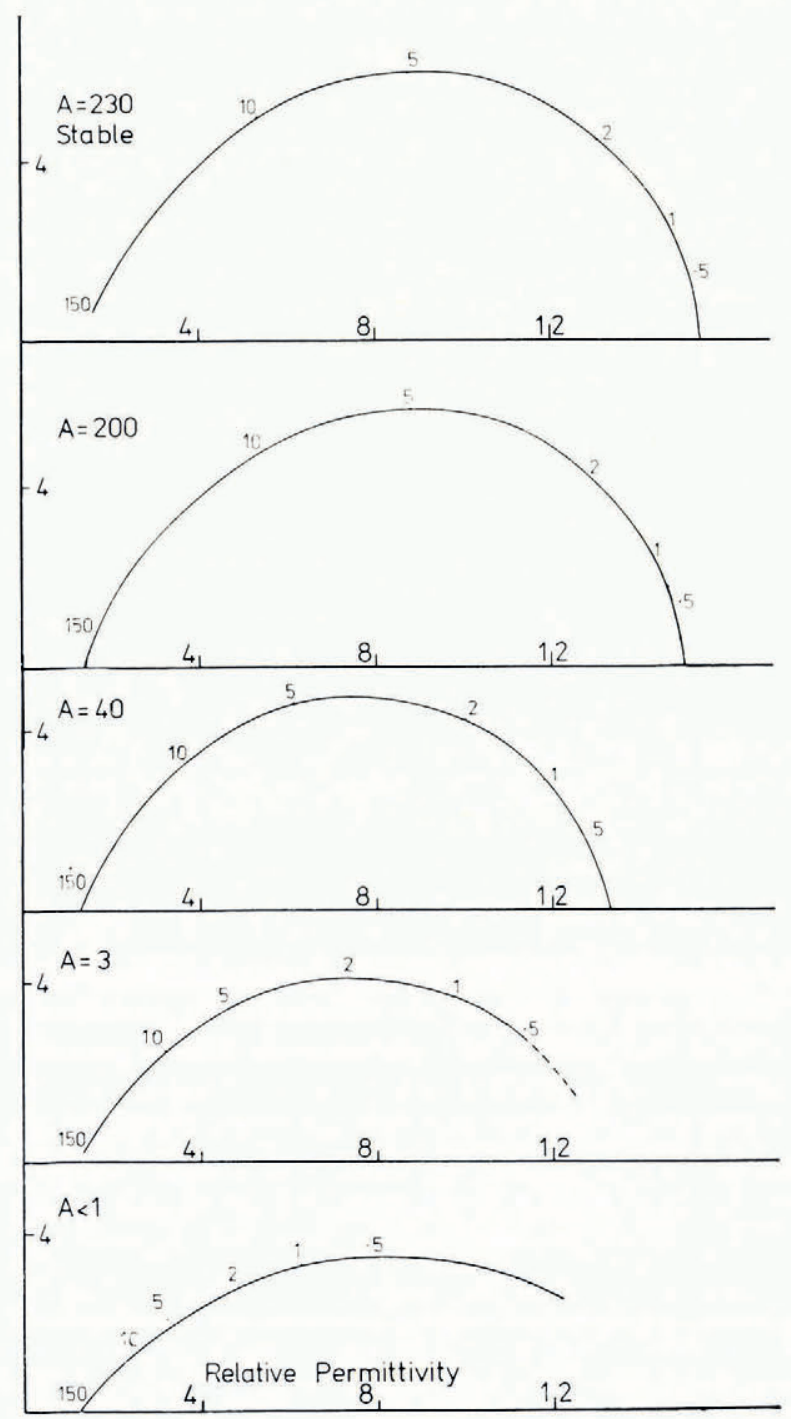

Fig. I. Progressive changes in the dielectric response of one sample of density $0.4^{\mathrm{I}} \mathrm{Mg} \mathrm{m}^{-3}$ monitored at $-44^{\circ} \mathrm{C}$ after storage at $-7^{\circ} \mathrm{C}$. Frequencies are in $\mathrm{kHz}$, and $A$ is the total number of hours for which the sample was stored at $-7^{\circ} \mathrm{C}$ before measurement. 
comparison with the experiments of Fujino and to approach the density range found in the surface firn of cold polar ice sheets. Preliminary results of our investigation were reported by Fitzgerald and others (1977).

\section{Results}

After compression, the samples were normally maintained at $-7^{\circ} \mathrm{C}$ and significant changes occurred to the dielectric response over the next few hours. During this annealing period, the snow bonded itself to the electrodes and, after a period of between 2 and $7 \mathrm{~d}$, the behaviour stabilized. The changes occurring during this period could be slowed down by lowering the storage temperature and the ageing process was effectively stopped by a temperature of $-17^{\circ} \mathrm{C}$. By cycling one sample derived from single-crystal ice from -7 to $-45^{\circ} \mathrm{C}$, and hence obtaining information on activation energies, more was learned about the progress of the ageing phenomenon. Figure I demonstrates how the measurements at $-44^{\circ} \mathrm{C}$ progressively change and stabilize after various numbers of hours storage at $-7^{\circ} \mathrm{C}$. There is a separation of the broad dispersion into two distinct dispersions and the relaxation frequency of the dominant lower-frequency dispersion increases. From measurements at different temperatures below $-7^{\circ} \mathrm{C}$, the activation energy for the mean relaxation frequency of the broad dispersion has a value of $0.30 \mathrm{eV}$ for the first cycle but falls to $0.24 \mathrm{eV}$ for the dominant dispersion after $9 \mathrm{~d}$ storage at $-7^{\circ} \mathrm{C}$. This ageing process requires further investigation. The remainder of this paper will be concerned with the behaviour of the firn once it has stabilized.

Fitzgerald and others (1977) modelled the stable behaviour of the five samples investigated as a simple Debye dispersion and noted the presence of a higher-frequency dispersion. The relaxation frequency of the dominant dispersion had an activation energy of $0.25 \pm 0.02 \mathrm{eV}$, which extrapolated to $c .30 \mathrm{kHz}$ at $0^{\circ} \mathrm{C}$, agreeing well with Fujino's values. The scatter in the relaxation frequency between the five samples is small and independent of the source of the constituent ice (Fig. 2). This important result shows that shaving and ageing destroys the difference in behaviour between deep polar ice and single crystals of ice in bulk by shortening the relaxation time to a common value. The activation energy of this relaxation is the same as that obtained for the dominant dispersion in bulk polar ice, but at $0.26 \mathrm{eV}$ it differs from the value of $0.6 \mathrm{eV}$ observed in the monocrystals.

To understand in greater detail the high-frequency dispersion, a statistical analysis has been performed on the measured response with models of dielectric behaviour. The leastsquares analysis is based on a modified Marquardt algorithm and uses the computer library NAGLIB sub-routine Eo4GAF devised by the Nottingham Algorithm Group. This analysis ensures rapid convergence of the adjustable parameters in the dielectric model to the values which give the best fit to the pairs of values of permittivity and conductivity of the snow, $\left(\epsilon_{i}, \sigma_{i}\right)$, corresponding to $\mathcal{N}$ (normally 2I) frequencies in the range $60 \mathrm{~Hz}$ to $200 \mathrm{kHz}$. The residual which the routine minimized was chosen to be

$$
R=\left\{\frac{\mathrm{I}}{\mathcal{N}} \sum_{i=1}^{\mathcal{N}}\left[\left(\mathrm{d} \epsilon_{i} / \epsilon_{i}\right)^{2}+\left(\mathrm{d} \sigma_{i} / \sigma_{i}\right)^{2}\right]\right\}^{\frac{1}{2}},
$$

where the model predicted $\left(\epsilon_{i}+\mathrm{d} \epsilon_{i}, \sigma_{i}+\mathrm{d} \sigma_{i}\right)$ in place of $\left(\epsilon_{i}, \sigma_{i}\right)$.

A dielectric with a high-frequency permittivity $\epsilon_{\infty}$ which relaxes according to the Debye dispersion law with dispersion strength $\Delta \epsilon$ and relaxation time $\tau$ may be represented by a complex permittivity $\epsilon$ defined by $\epsilon \equiv \epsilon^{\prime}-\mathrm{j} \epsilon^{\prime \prime}=\epsilon_{\infty}+(\Delta \epsilon / 2)(\mathrm{I}+\exp (-\mathrm{j} \theta))$ where $\theta / 2=$ $\tan ^{-1} \omega \tau$ and $\omega$ is the angular frequency. The complex-plane plot of this dispersion is semicircular. More complicated dispersions occur when there is a spread of relaxation times between two limits $\tau_{\mathrm{h}}$ and $\tau_{\mathrm{l}}$. If the spread is uniformly distributed on a logarithmic time scale, as could occur experimentally if a Debye dielectric was in a uniform temperature 




Fig. 2. Temperature dependence of the relaxation frequency obtained graphically for the dominant dispersion (2) in five aged synthetic snow samples. $I, \rho=0.42 \mathrm{Mg} \mathrm{m}^{-3} ; 2, \rho=0.43 \mathrm{Mg} \mathrm{m}^{-3} ; 3, \rho=0.38 \mathrm{Mg} \mathrm{m}^{-3} ; 4, \rho=0.44 \mathrm{Mg} \mathrm{m}^{-3}$; $5, \rho=0.41 \mathrm{Mg} \mathrm{m}^{-3}$. Sample 4 was prepared from "Byrd" station ice, the remainder from pure monocrystals. The relaxation behaviour measured by Fujino is the line FF.

gradient, the dispersion may be treated analytically. Defining $\tau$ as the logarithmic mean relaxation time $\left(\ln \tau=\frac{1}{2}\left[\ln \tau_{\mathrm{h}}+\ln \tau_{1}\right]\right)$ and defining a spreading factor $\alpha$ by $\ln \tau_{\mathrm{h}}-\ln \tau_{1}$, we obtain

$$
\epsilon^{\prime}-\mathrm{j} \epsilon^{\prime \prime}=\epsilon_{\infty}+(\Delta \epsilon / 2)\left[\mathrm{I}+(2 / \alpha) \ln \frac{\mathrm{I}+\exp (-\mathrm{j} \theta) \tanh \frac{1}{4} \alpha}{\mathrm{I}-\exp (-\mathrm{j} \theta) \tanh \frac{1}{4} \alpha}\right],
$$

where $\theta / 2=\tan ^{-1} \omega \tau$.

At frequencies well above the mean relaxation frequency, $F\left(F^{-1} \equiv 2 \pi \tau\right)$, the conductivity becomes independent of frequency and is given by

$$
\Delta \sigma=\left(2 \pi \epsilon_{0} F \Delta \epsilon \sinh \frac{1}{2} \alpha\right) / \frac{1}{2} \alpha,
$$

where $\epsilon_{0}$ is the electric constant.

This semi-elliptical dispersion was first discussed in the context of the dielectric behaviour of ice clathrates by Gough and others (1974), who attributed it to Fröhlich.

We have modelled the behaviour of three of our samples by a series of up to three elliptical dispersions with unknown parameters $\Delta \epsilon_{i}, F_{i}$, and $\alpha_{i}$; by setting any $\alpha_{i}$ equal to zero in the 


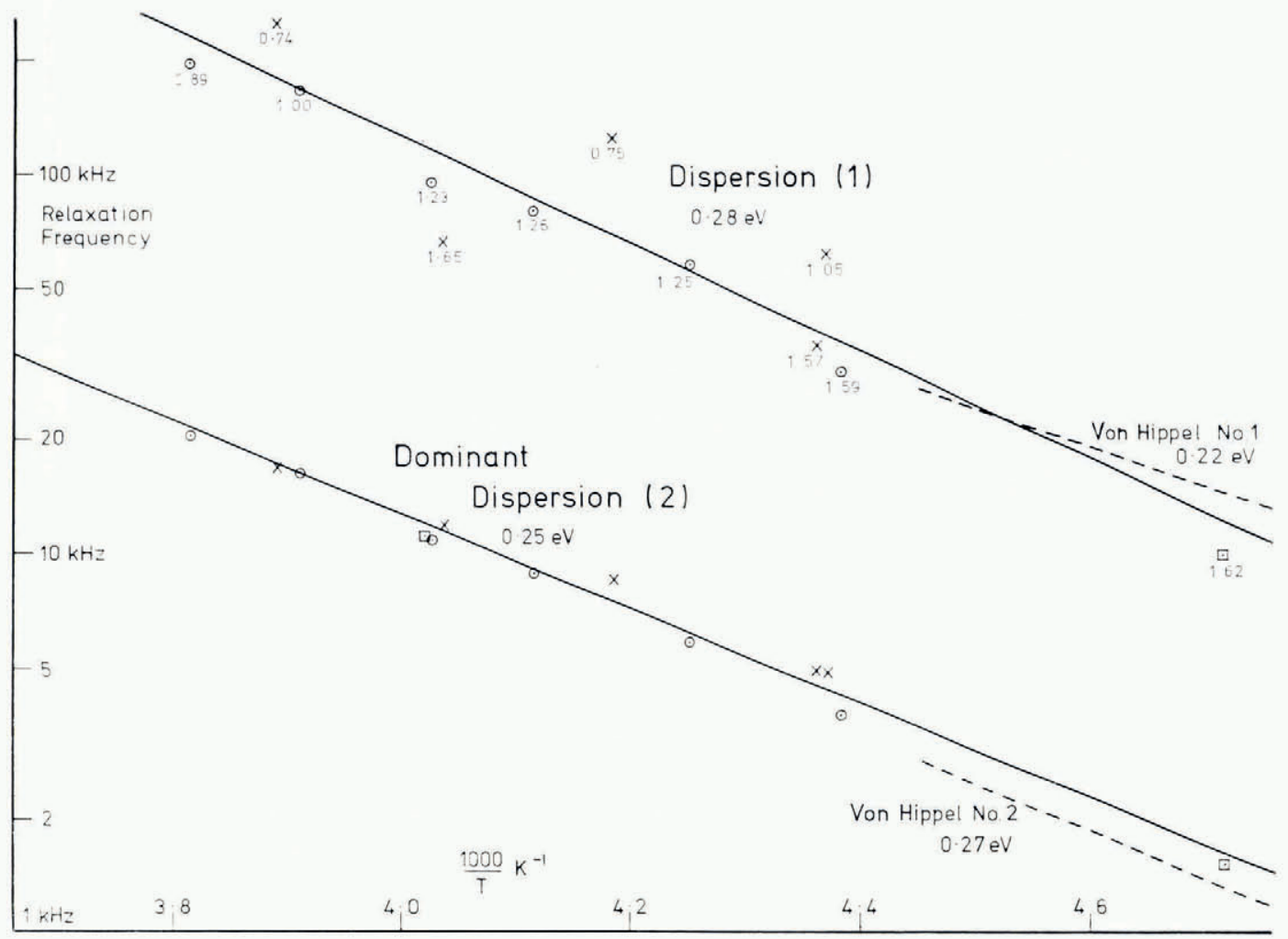

Fig. 3. Temperature dependence of the mean relaxation frequencies obtained by computer modelling of the high-frequency dispersion $(I)$ and dominant dispersion (2) in three aged synthetic snow samples. $\square=I, \odot=4, \times=5$. The corresponding $\Delta \epsilon_{1}$ values are given for dispersion $(I)$. Sample 4 was prepared from "Byrd" station ice, samples $I$ and 5 from pure monocrystals. The best-fit line for each dispersion is given.

analysis, a Debye dispersion follows. Dispersion ( $\mathrm{I}$ ) is the high-frequency dispersion, dispersion (2) is the dominant dispersion, and dispersion (3), more evident at high temperatures, is probably caused by space-charge effects.

In Figure 3, the derived values of the relaxation frequencies $F_{1}$ and $F_{2}$ are given for the three samples, I, 4, and 5 . These samples were chosen for analysis, because of the similarity of their $F_{2}$ values in Figure 2. This more sophisticated approach to the dominant dispersion (2) reliably confirms the original relaxation-frequency values and derives spreading-factor values, $\alpha_{2}$, in the range $\mathrm{I} .0<\bar{\alpha}_{2}=\mathrm{I} .6<2.3$. There is scatter in the values of $F_{\mathrm{I}}, \Delta \epsilon_{\mathrm{I}}$, and $\alpha_{\mathrm{I}}$, and the corresponding $\Delta \epsilon_{\mathrm{I}}$ values are given beside the $F_{\mathrm{I}}$ points in Figure 3 . There is a trend in the scatter for lower $\Delta \epsilon_{\mathrm{I}}$ values to be associated with higher $F_{\mathrm{I}}$ values. This compensation is demonstrated in the lack of scatter in the conductivity increase through this dispersion, $\Delta \sigma_{1}$, derived from Equation (I). Curiously, our analysis produces similar values for $\Delta \sigma_{\mathrm{I}}$ and $\Delta \sigma_{2}$ for each temperature. In Figure 4 the data for the three samples have been combined and the strength of each dispersion is compared with the conductivities, $\Delta \sigma_{1}, \Delta \sigma_{2}$, and $\left(\Delta \sigma_{1}+\Delta \sigma_{2}\right)$, for the dense polar ice from I $424 \mathrm{~m}$ depth from "Byrd" station, used as the basis for sample 4. The equality of the values of $\Delta \sigma_{1}$ and $\Delta \sigma_{2}$ for the three snow samples essentially follows from the fact that $F_{1} \approx 10 F_{2}$ and $\Delta \epsilon_{1} \approx \frac{1}{10} \Delta \epsilon_{2}$.

We will now discuss in turn the possible origin of these two dispersions observed in compressed finely divided ice. 


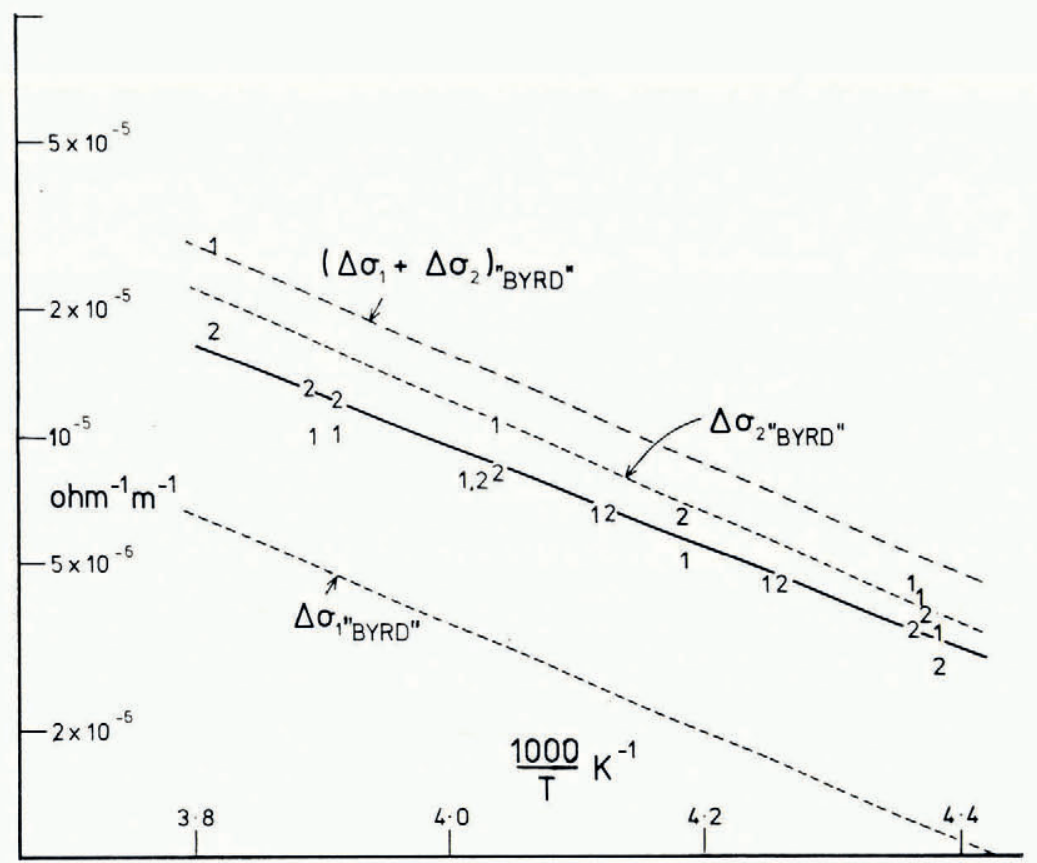

Fig. 4. Temperature dependence of the dispersion in conductivity $\Delta \sigma_{1}$ of the high-frequency dispersion and $\Delta \sigma_{2}$ of the dominant dispersion for the samples of Figure 3. The symbols $I$ and 2 refer to $\Delta \sigma_{1}$ and $\Delta \sigma_{2}$ values. The values $\Delta \sigma_{1}, \Delta \sigma_{2}$, and $\left(\Delta \sigma_{1}+\Delta \sigma_{2}\right)$ for the polar ice from I $424 m$ at "Byrd" station, used as a basis of sample 4 , are given for comparison as dashed lines.

\section{DisGuSSION OF DIELEGTRIG RESPONSE}

\section{The high-frequency dispersion (I)}

Glen and Paren (1975) have already shown that the Böttcher and Looyenga mixture models for a composite dielectric made up of air and an ice-like material, approximated by the Debye dispersion, predict a dispersion that deviates from a semi-circular Cole-Cole plot at high frequencies. This deviation is due to interfacial polarization within the heterogeneous material, properly called the Maxwell-Wagner dispersion. We wish to question whether the high-frequency dispersion that we observe is due to Maxwell-Wagner effects as has been attributed to the corresponding dispersion in artificial sea ice (Addison, 1970) or reflects an inherent process in the ice, for example, one of the higher-frequency dispersions observed by Von Hippel and others (1972) in pure ice or in HF-doped ice by Camplin and Glen (1973). To do this, we first use the most general dielectric formula for mixtures to discuss the relaxation frequency of the high-frequency dispersion. We follow this discussion by demonstrating the predictions of the specific Böttcher and Looyenga models.

We have shown in Figure 3 that the activation energies for the relaxation frequencies in the high-frequency and dominant dispersions are similar as far as the best-fit lines are concerned, so the ratio of the relaxation frequencies varies only slightly with temperature, having a value of $\mathrm{I} .5$ at $0^{\circ} \mathrm{C}$ and 7.5 at $-60^{\circ} \mathrm{C}$. If the high-frequency dispersion is solely due to interfacial polarization, the ratio should be almost independent of temperature. Our general considerations will show that the ratio should lie between 9 and 25 , making it plausible that the high-frequency dispersion is due to Maxwell-Wagner effects. 
The most general calculation for the complex permittivity $\epsilon$ for any random mixture of dielectric of complex permittivity $\epsilon_{2}$ dispersed with volume fraction $v_{2}$ with shape factors $A_{1}, A_{2}$, and $A_{3}$ within a medium of complex permittivity $\epsilon_{\mathrm{I}}$ is given by

$$
\epsilon-\epsilon_{\mathrm{I}}=\frac{1}{3} v_{2} \sum_{i=1}^{3}\left[E^{-1}+C_{i}^{-1}\right]^{-1},
$$

where the complex quantity

$$
E=\epsilon_{2}-\epsilon_{1},
$$

and the complex quantity

$$
C_{\mathrm{i}}=\left[\bar{\epsilon}_{i} / A_{i}\right]\left(\epsilon_{2}-\epsilon_{\mathrm{1}}\right) /\left(\epsilon_{2}-\bar{\epsilon}_{\mathrm{I}}\right),
$$

where the quantity $\bar{\epsilon}_{\mathrm{I}}$ is the permittivity of the immediate surroundings of the dispersed dielectric. An equation of this type was first derived by Polder and van Santen (1946), and Equation (2) was derived subsequently by different arguments by Beek ( 1967 ) and Loor (unpublished). Loor stated "no method of calculating $\bar{\epsilon}_{\mathrm{I}}$ has been found which is universally valid, and the assumptions made in the literature are usually very inadequately discussed". Theorists agree that $\bar{\epsilon}_{\mathrm{I}}$ must be intermediate in value between $\epsilon_{\mathrm{I}}$ and $\epsilon$.

In the classic Maxwell-Wagner dispersion, the Debye dispersion results when the two interacting dielectrics have frequency-independent permittivities and conductivities. Such a frequency independence is anticipated in air and "pure" ice in the frequency range under consideration in the absence of higher-frequency ice dispersions, and we will enforce such a frequency independence to the ice of our samples by making the approximation that the complex quantities $E$ and $C_{i}$ appearing in Equation (2) are accurately represented by frequency-independent quantities of dimensions permittivity and conductivity $\left(E^{\prime}, \sigma_{E}\right)$, $\left(C_{i}^{\prime}, \sigma_{C i}\right)$. With this proviso, Equation (2) predicts three Debye dispersions with relaxation frequencies given by:

$$
F_{M W i}=\left(2 \pi \epsilon_{0}\right)^{-1}\left(\sigma_{C i}+\sigma_{E}\right) /\left(C_{i}^{\prime}+E^{\prime}\right),
$$

and the ratio of relaxation frequencies of the Maxwell-Wagner dispersion to the main dispersion in snow is

$$
F_{M W i} / F=\left[\left(\sigma_{C i}+\sigma_{E}\right) / \sigma_{\infty_{s}}\right] \Delta \epsilon_{\mathrm{s}} /\left(C_{i}^{\prime}+E^{\prime}\right),
$$

where we assume the main dispersion follows the Debye dispersion of dispersion strength $\Delta \epsilon_{\mathrm{S}}$ and high-frequency conductivity $\sigma_{\infty_{\mathrm{s}}}$.

Finely divided ice in the density range $0.4^{2}$ to $0.46 \mathrm{Mg} \mathrm{m}^{-3}$ contains roughly equal volumes of ice and air, and may be modelled by ice inclusions in air $(I / A)$ or air inclusions in ice $(A / I)$. We make the assumption used successfully before, when considering the highfrequency permittivity of snow, that the inclusions may be treated as spheres (Glen and Paren, 1975). In this case $A_{i}=\frac{1}{3}$ and the terms in the summation in Equation (2) become identical, and a single relaxation frequency results. Since we have measurements or good estimates of the permittivity of snow, $\epsilon_{\infty}$, and the ratio of the conductivity of snow to ice at high frequencies, $\sigma_{\infty_{\mathrm{s}}} / \sigma_{\infty_{\mathrm{i}}}$, we may substitute these values in the complex form of Equation (2) to deduce the unknown values of $\sigma_{C}, C^{\prime}$ (and hence $\bar{\epsilon}_{1}$ ), which cannot be calculated $a$ priori. This calculation of the values $\sigma_{C}$ and $C^{\prime}$ is possible since the permittivities of ice and air are well known. These values are then used in Equation (4) to calculate the ratio of the relaxation frequencies. In Table I the relevant values are given for the different geometries, densities and conductivity estimates.

Table I shows a significant change in the calculated values of $F_{M W} / F$ when only small variations are made in either the value of the permittivity or conductivity of the snow. Nonetheless, a consistent value of $F_{M W} / F$ of $I \mathrm{I}$ is obtained if the Looyenga model is used to predict the dispersion strength, high-frequency permittivity, and conductivity of the snow. The data from samples I, 4 , and 5 favour a value between 9 and 26 when $\sigma_{\infty_{s}} / \sigma_{\infty_{1}}$ is within the 


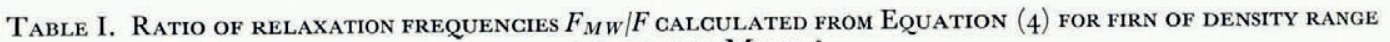

\begin{tabular}{|c|c|c|c|c|c|c|}
\hline $\begin{array}{c}\text { Density } \\
\mathrm{Mg} \mathrm{m}^{-3}\end{array}$ & $\epsilon_{\infty}$ & $\frac{\sigma_{\infty_{\mathrm{g}}}}{\sigma_{\infty_{1}}}$ & $\underset{\tilde{\epsilon}_{\mathrm{I}}}{A / I}$ & $\begin{array}{c}I / A \\
\bar{\epsilon}_{\mathrm{I}}\end{array}$ & $\Delta \epsilon_{\mathrm{s}}$ & $F_{M W} / F$ \\
\hline $0.4^{10}$ & 1.767 & 0.302 & 1. $75^{*}$ & 1. $7^{8 *}$ & 16.7 & I I. I \\
\hline 0.420 & 1. $79^{\circ}$ & 0.312 & 1. $78 *$ & 1.80* & 17.5 & 11.2 \\
\hline $0.43^{\circ}$ & 1. 812 & $0.3^{22}$ & 1. $81 *$ & 1. $82 *$ & 18.4 & I 1.4 \\
\hline $0.44^{\circ}$ & 1. 835 & $0.33^{2}$ & 1. $84^{*}$ & 1. $83^{*}$ & I9.3 & I I.7 \\
\hline \multirow[t]{3}{*}{0.410} & I. 700 & 0.300 & 2.19 & I. $4^{8}$ & I6.7 & $\begin{array}{l}21 \\
16\end{array}$ \\
\hline & $\begin{array}{l}\text { I. } 735 \\
\text { I. } 770\end{array}$ & & $\begin{array}{l}\text { 1.94 } \\
1.75^{*}\end{array}$ & $\begin{array}{l}\text { I.63 } \\
\text { 1. } 78 *\end{array}$ & & $\begin{array}{l}10 \\
\text { II }\end{array}$ \\
\hline & I.805 & & $1.55 \dagger$ & I. $98 \dagger$ & & 1. $3 \dagger$ \\
\hline \multirow[t]{2}{*}{0.417} & I. 700 & $0.25^{\circ}$ & 2.37 & I. 43 & 16.3 & I 3 \\
\hline & & 0.300 & & & & 21 \\
\hline \multirow[t]{3}{*}{0.444} & & $0.35^{\circ}$ & $260 t$ & 23 & & 26 \\
\hline & 1.090 & $\begin{array}{l}0.25^{\circ} \\
0.300\end{array}$ & $3.02 \top$ & 1.23 & 14.5 & $\begin{array}{l}16 \\
20\end{array}$ \\
\hline & & $0.35^{\circ}$ & & & & 22 \\
\hline \multirow[t]{3}{*}{$0.4^{1} 4$} & I.710 & $0.25^{\circ}$ & 2.18 & $1.5^{\mathrm{I}}$ & I3.6 & 9 \\
\hline & & 0.300 & & & & 16 \\
\hline & & $0.35^{\circ}$ & & & & 20 \\
\hline
\end{tabular}

Comments

$\epsilon_{\infty}, \Delta \epsilon_{\mathrm{s}}$ and $\sigma_{\infty_{\mathrm{s}}} / \sigma_{\infty_{1}}$ derived from the Looyenga model

See equations (8), (9), and (10) of Glen and Paren (1975)

As above with $\epsilon_{\infty}$ varied by $-4 \%$

$-2 \%$
$0 \%$

Sample I. Observed data with different estimates of $\sigma_{\infty_{s}} / \sigma_{\infty_{1}}$

Sample 4. Observed data with different estimates of $\sigma_{\infty_{s}} / \sigma_{\infty_{1}}$

Sample 5. Observed data with different estimates of $\sigma_{\infty_{s}} / \sigma_{\infty_{1}}$

For $A / I$ model $\bar{\epsilon}_{\mathrm{I}}$ should be in range $\epsilon_{\infty}<\bar{\epsilon}_{\mathrm{I}}<3.17$.

For $I / A$ model $\bar{\epsilon}_{\mathrm{I}}$ should be in range $\mathrm{I}<\bar{\epsilon}_{\mathrm{I}}<\epsilon_{\infty}$.

* In the Looyenga model $\bar{\epsilon}_{\mathrm{I}}$ is seen to be equal to $\epsilon_{\infty}$ with minimal error.

$\dagger \bar{\epsilon}_{\mathrm{I}}$ is markedly beyond the range expected, invalidating the analysis.

reasonable range $0.30 \pm 0.05$, and the experimental values of $F_{M W} / F$ from Figure 3 are in the range 6-1 7 with a mean of 9.5 . The same values of $F_{M W} / F$ are obtained whether the snow is considered to contain ice or air inclusions. The approximations we have made in developing this model are restrictive if the relaxation frequencies of the two dispersions differ by less than a factor of ten; we cannot expect the frequency independence of permittivity and conductivity of the ice throughout the high-frequency dispersion. We will therefore not pursue this model further in discussing other aspects of this dispersion. Nevertheless, these crude calculations have shown that it occupies the frequency range anticipated for the Maxwell-Wagner dispersion.

Our second approach to the origin of the stable high-frequency dispersion in finely divided ice considers the complete relaxation spectrum of one sample. Measurements were made on two occasions near $-44^{\circ} \mathrm{C}$; first at $-44.2^{\circ} \mathrm{C}$ and one week later, after having been cycled to $-7^{\circ} \mathrm{C}$, at $-44.5^{\circ} \mathrm{C}$. The density of the sample was $0.4{ }^{\mathrm{I}} 4 \mathrm{Mg} \mathrm{m}^{-3}$ and the measurements, which were practically identical, are the upper two spectra in Figure I. Table II represents the model parameters of the two dispersions of which each spectrum is composed. Modelling the dispersions as Debye dispersions, there is no essential difference between the derived parameters for the two experiments. Nevertheless, in the significantly better fit using semielliptical dispersions, the parameters derived for the high-frequency dispersion show more

Table II. Parameters of dispersions of finely divided ice, ice component and polar ice at $c .-45^{\circ} \mathrm{C}$

\begin{tabular}{|c|c|c|c|c|c|c|c|c|c|c|c|c|}
\hline Description & $\begin{array}{c}\text { Temperalure } \\
{ }^{\circ} \mathrm{C}\end{array}$ & $\epsilon \infty$ & $\Delta \epsilon_{\mathrm{I}}$ & $\underset{\mathrm{kHz}}{F_{1}}$ & $\alpha_{1}$ & $\Delta \epsilon_{2}$ & $\begin{array}{c}F_{2} \\
\mathrm{kHz}\end{array}$ & $\alpha_{2}$ & $\Omega^{-1} \frac{\Delta \sigma_{\mathrm{I}}}{\mathrm{m}^{-1}}$ & $\begin{array}{c}\Delta \sigma_{2} \\
\Omega^{-1} \mathrm{~m}^{-1}\end{array}$ & $\begin{array}{l}\Delta \sigma_{1}+\Delta \sigma_{2} \\
\Omega^{-1} \mathrm{~m}^{-1}\end{array}$ & $\begin{array}{l}\text { error per } \\
\text { point } \%\end{array}$ \\
\hline Snow & $-44 \cdot 5$ & 1. 76 & $1.5^{2}$ & $45 \cdot 3$ & o & 12.32 & $4 \cdot 56$ & 0 & $\begin{array}{l}3.85 \times 10^{-6} \\
3.86 \times 10^{-6}\end{array}$ & $3.14 \times 10^{-6}$ & $\begin{array}{l}6.99 \times 10^{-6} \\
6.81 \times 10^{-6}\end{array}$ & 3 \\
\hline $\begin{array}{l}\text { Snow } \\
\text { Snow }\end{array}$ & -44.2 & 1.77 & 1.62 & 43.2 & o & $1 \mathrm{r} .8 \mathrm{I}$ & 4.63 & 0 & $\begin{array}{l}3.86 \times 10^{-6} \\
4.04 \times 10^{-6}\end{array}$ & $\begin{array}{l}2.94 \times 10^{-6} \\
3.76 \times 10^{-6}\end{array}$ & $7.80 \times 10^{-6}$ & $\begin{array}{l}3 \\
1\end{array}$ \\
\hline $\begin{array}{l}\text { Snow } \\
\text { Snow }\end{array}$ & $\begin{array}{l}-44.5 \\
-44.2\end{array}$ & $\begin{array}{l}1.72 \\
1.71\end{array}$ & $\begin{array}{l}1.05 \\
1.57\end{array}$ & $\begin{array}{l}61.7 \\
36.8\end{array}$ & $\begin{array}{l}1.69 \\
2.87\end{array}$ & $\begin{array}{l}12.72 \\
11.59\end{array}$ & $\begin{array}{l}4.87 \\
4.83\end{array}$ & $\begin{array}{l}1.4^{8} \\
1.59\end{array}$ & $4.44 \times 10^{-6}$ & $3.48 \times 10^{-6}$ & $7.92 \times 10^{-6}$ & I \\
\hline Ice: Böttcher & $-44 \cdot 5$ & 3.09 & I. 57 & 59.6 & 0 & 72.59 & 4.26 & 1.74 & $5.19 \times 10^{-6}$ & $1.94 \times 10^{-5}$ & $2.46 \times 10^{-5}$ & I \\
\hline Ice: Looyenga & $-44 \cdot 5$ & 3.03 & 1.60 & 73.9 & $0.5^{80}$ & 77.90 & 4.17 & $0.9^{8}$ & $6.65 \times 10^{-6}$ & $1.87 \times 10^{-5}$ & $2.54 \times 10^{-5}$ & I \\
\hline Ice: Böttcher & -44.2 & 3.19 & I. 73 & 66.8 & 0.013 & 69.10 & $4 \cdot 53$ & I.I I & $6.43 \times 10^{-6}$ & $1.83 \times 10^{-5}$ & $2.47 \times 10^{-5}$ & 3 \\
\hline Ice: "Byrd" station & -45.5 & 2.98 & $3 \cdot 39$ & $5 \cdot 99$ & 0 & 99.80 & $0.5^{8}$ & $2.4^{1}$ & $1.13 \times 10^{-6}$ & $4.05 \times 10^{-6}$ & $5.18 \times 10^{-6}$ & I \\
\hline
\end{tabular}


divergence between the two measurement sets although the quality of the fit is similar. We interpret this as giving a realistic range of uncertainty of the values $\Delta \epsilon_{1}, F_{1}$, and $\alpha_{1}$ around $-44^{\circ} \mathrm{C}$ than supporting a difference in behaviour between the two experiments.

We may compare in Table II the values of these parameters with those we calculate as attributable to the ice component of the heterogeneous ice-air system. We have used Böttcher and Looyenga mixture equations to derive the dielectric behaviour of the ice from the observed behaviour of the snow. In Figure 5 the ice behaviour derived from the Böttcher model for the first experiment is contrasted with that obtained from a Looyenga model for the subsequent experiment.

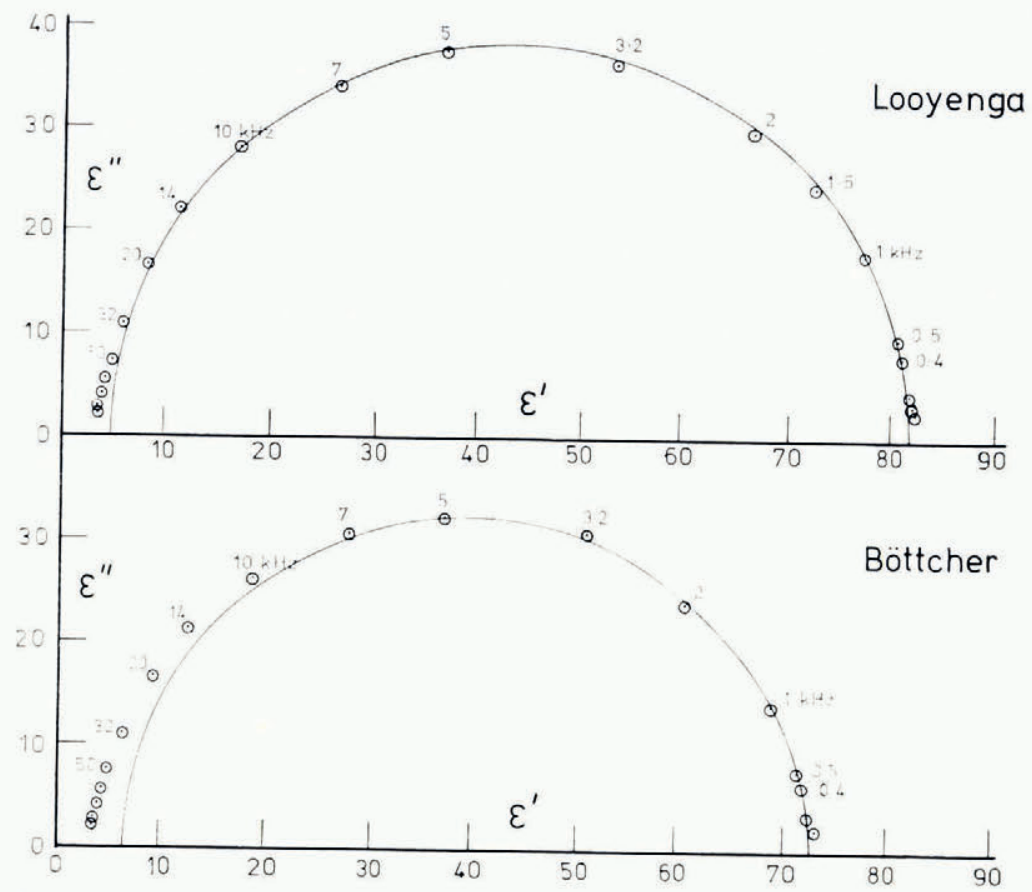

Fig. 5. The dielectric response at c. $-44^{\circ} \mathrm{C}$ of the ice component alone of a sample of density $0.4 \mathrm{I} \mathrm{Mg} \mathrm{m}^{-3}$ calculated from the measured behaviour assuming two dielectric mixture formulae discussed by Glen and Paren (I975). (I) Looyenga model, $-44 \cdot 4^{\circ} \mathrm{C}$. (2) Böttcher model, $-44.2^{\circ} \mathrm{C}$. Frequencies are in $\mathrm{kHz}$.

It is instructive to compare the behaviour of the snow and that derived for the ice component alone with that of a dense polar sample taken from I $424 \mathrm{~m}$ depth from the drill hole at "Byrd" station, Antarctica. Measurements on other samples from this depth of core have been reported by Fitzgerald and Paren (1975) and on other samples from "Byrd" station by Maeno (I974[a], [b]). Further experiments on "Byrd" station core were undertaken in the same cell used for the finely divided ice experiments to cover the dispersion in greater frequency detail than hitherto.

The dielectric dispersion at $-45^{\circ} \mathrm{C}$ is presented in Figure 6 and demonstrates that the principal dispersion is semi-elliptical. A depressed circular arc is included in the figure for comparison, since this was one of the models used by Fitzgerald and Paren (1975) to analyse the earlier measurements. One failure in using the depressed arc model for describing polar ice cores is that the model conductivity does not become constant at high frequencies, whereas experimental evidence shows negligible dispersion between the mid $\mathrm{kHz}$ and high $\mathrm{MHz}$ range. 


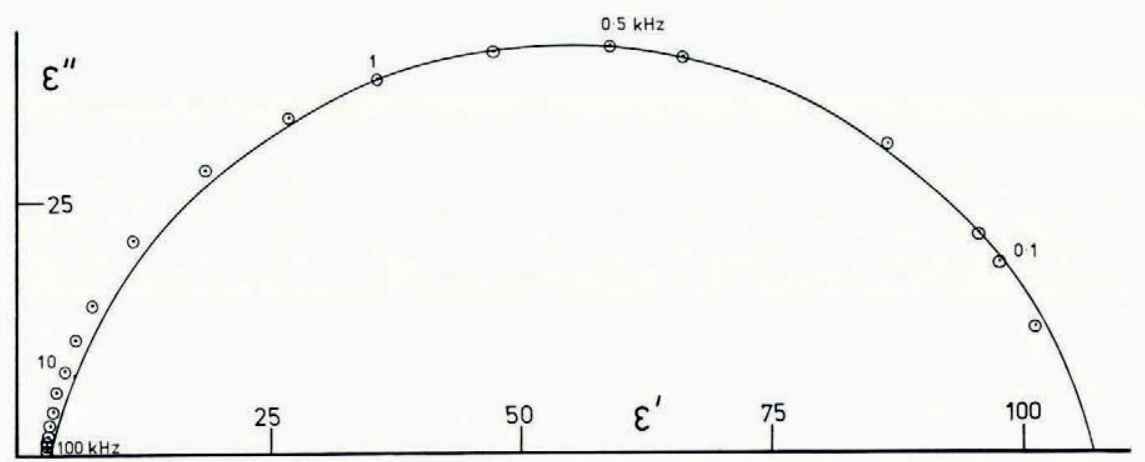

Fig. 6. The dielectric response at $-45^{\circ} \mathrm{C}$ of ice from $\mathrm{I} 424 \mathrm{~m}$ depth from "Byrd" station, Antarctica. A circular arc has been drawn on the diagram to emphasize the elliptical response. Nevertheless, this dispersion is best fitted to two elliptical dispersions.

The dispersion of Figure 6 is best represented nevertheless by two spectra. The derived parameters for this figure are given in Table II, and Figures 4 and 7 depict the temperature dependence of the conductivities and relaxation frequencies for this sample. In common with earlier investigations, summarized by Glen and Paren (1975), the conductivity at high frequencies $\left(\Delta \sigma_{1}+\Delta \sigma_{2}\right)$ has an activation energy of $0.26 \mathrm{eV}$ and the conductivity extrapolates at the melting point to $4.40 \times 10^{-5} \Omega^{-1} \mathrm{~m}^{-1}$. The conductivity at the melting point is the same as that observed in pure single crystals of ice. This analysis however gives different values to

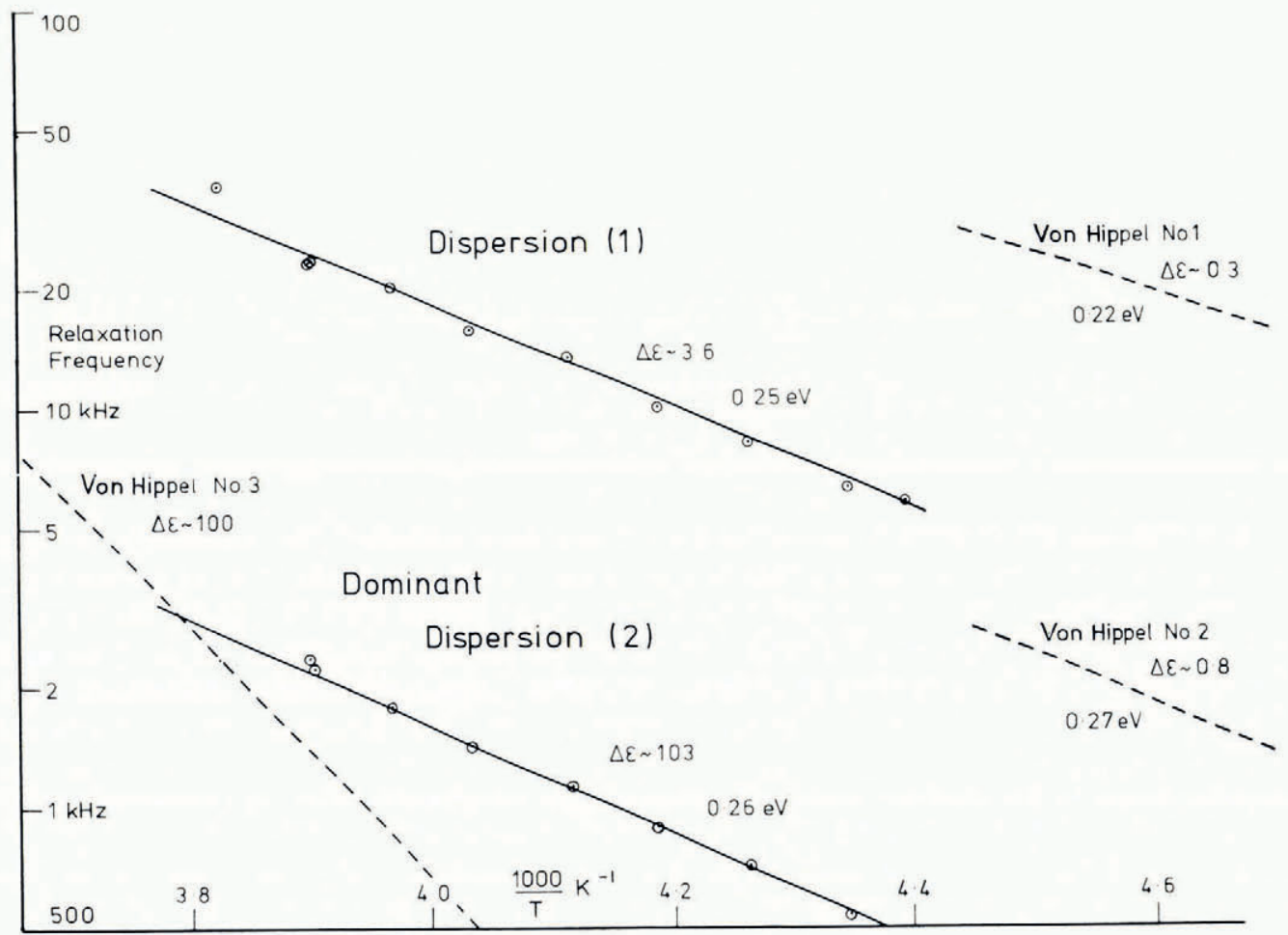

Fig. 7. Temperature dependence of the mean relaxation frequencies obtained by computer modelling of the high-frequency dispersion ( $I$ ) and dominant dispersion (2) in ice from $144^{2} 4 \mathrm{~m}$ depth from "Byrd" station. 
$F_{2}$ and $\Delta \epsilon_{2}$ than those calculated for a polar sample from I $050 \mathrm{~m}$ depth from "Camp Century", Greenland, measured between insulating films at each electrode (Paren, r973).

The ice-component dispersion derived using the Looyenga model of the compressed snow in Figure 5 gives the visual appearance of a single Debye dispersion, compared with the pair of spectra in the original snow and in the ice component derived for the Böttcher model. If the high-frequency spectrum were to have been completely absent in the ice derived from the Looyenga model, it would have confirmed that this spectrum in the snow was a MaxwellWagner dispersion, and moreover confirmed that the Looyenga model accurately represented the heterogeneous ice-air system. Nevertheless, the computer analyses of the ice components derived from both the Böttcher and Looyenga models still reveal the existence of a highfrequency dispersion, and what is surprising is that the values for $\Delta \epsilon_{\mathrm{I}}$ and $F_{\mathrm{I}}$ are similar to those found in the original snow. In the snow $\Delta \epsilon_{1} \approx 1.50, F_{1} \approx 48 \mathrm{kHz}$; in the Böttcher and Looyenga ice, $\Delta \epsilon_{1} \approx 1.62, F_{1} \approx 67 \mathrm{kHz}$. The spreading factor $\alpha_{1}$ is smaller in the ice than in the snow. This fact alone gives conviction to the view that there is a real dispersion in the ice and its frequency domain overlaps the Maxwell-Wagner dispersion in the snow. The problem may be resolved by carrying out the experiment with the snow sample impregnated with a liquid dielectric rather than air; the effect of this would be to displace the MaxwellWagner dispersion. As Figure 3 shows, Von Hippel and others (1972) have derived by computer analysis a subspectrum, number $\mathrm{I}$, in the response of single crystals, which is in this frequency domain. They have no evidence for this dispersion above $-50^{\circ} \mathrm{C}$; at lower temperatures the activation energy is $0.22 \mathrm{eV}$ and the permittivity dispersion is around 0.3 .

\section{Dominant dispersion (2)}

We will take it as axiomatic that the dominant dispersion is due to the bulk relaxation of the ice component; indeed, within the bounds of uncertainty set by dielectric mixture models, it is encouraging that the dispersion strength of the ice phase, $\Delta \epsilon_{2}$, is calculated to be around 70 in Table II, approaching the value known for bulk ice. The relaxation frequency $F_{2}$ of the ice component derived using the Böttcher and Looyenga models is virtually the same as that of the composite snow (Table II), so we may compare the relaxation frequency of the snow with those of other dispersions in ice and snow of differing densities (Table III). This selective compilation highlights the occurrence of spectra in this frequency domain, suggesting a common cause for the observed frequency, with the dispersion strength being dependent on the structure of individual samples. Tentatively, we relate the structure dependence to the presence of ice-air interfaces and assert that, within a region bounded by such an interface, water molecules re-orient at a faster fixed rate and independently of the bulk ice. With such an interpretation, the snow of our samples is sufficiently fine for the whole response to be determined by the surfaces. This is not the case in polar ice or in certain single crystals where this response occurs in addition to the bulk response.

TABle III. Relaxation SPECtra in SNOW AND SUB-SPECTRA OF ICE

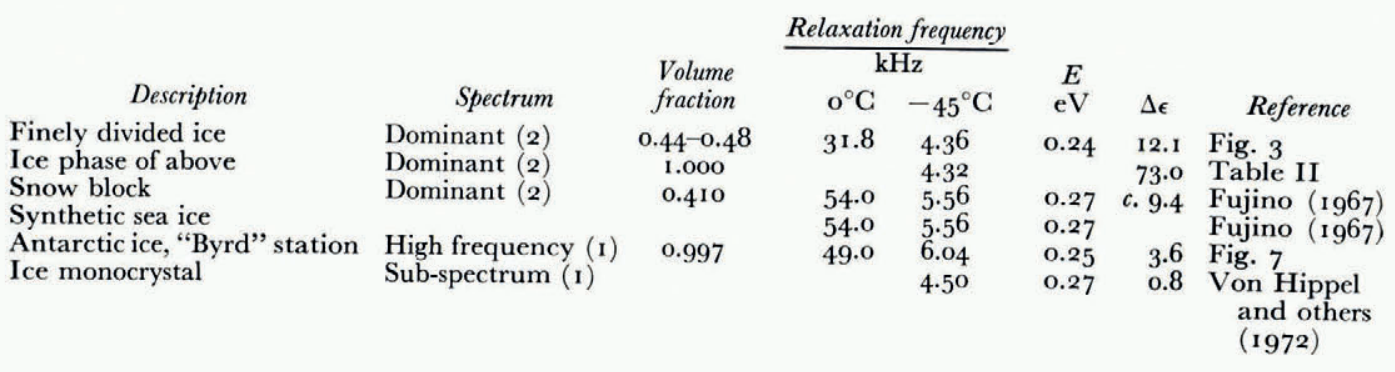


Let us consider the implications of this suggestion by considering the variations of surface area that occur during the metamorphism of freshly fallen snow and through the densification of firn with increasing depth in cold polar ice sheets. Adamson and others (1967) measured by nitrogen adsorption a surface area of $200 \mathrm{~m}^{2} \mathrm{~kg}^{-1}$ for "falling snow powder" at $2500 \mathrm{~m}$ on Mount San Gorgonio, and $400 \mathrm{~m}^{2} \mathrm{~kg}^{-1}$ for day-old snow in Denver; these values were about those expected from the geometry of the ice. No nitrogen adsorption has been reported on ice from the polar regions; however, very careful measurements by Gow (197I) on ice-core samples have demonstrated that the growth of crystals is analogous to isothermal grain growth in metallic and ceramic sinters. The following relationship is obeyed:

$$
D^{2}=D_{0}^{2}+k t,
$$

where $D^{2}$ is the mean cross-sectional area of the firn crystals, $t$ is the age of the firn, $D_{0}{ }^{2}$ is the mean cross-section extrapolated to zero age, and $k$ is the observed rate of growth of firn crystals.

By studying cores from a wide range of in situ temperatures, the value of $k$ was found to follow the Arrhenius relationship with activation energy $0.46 \mathrm{eV}$. There is an enhanced rate of crystal growth in the top few metres of firn due to seasonal temperature waves, and $D_{0}{ }^{2}$, the "zero-age" crystal size, is not the crystal size at the surface but rather at a depth of $2-5 \mathrm{~m}$, where the ice-volume fraction averages about 0.50. After prolonged densification, the network of air passages in the firn becomes sealed off and the firn becomes impermeable ice. At this transition, the ice-volume fraction is 0.90 and there appear to be equal numbers of bubbles and crystals. With this information, and further data of Gow (I97I), we may calculate a specific surface area for four polar sites both near the surface where $v$ averages $0.5^{\circ}$ and at the firn-ice transition. $D_{\mathrm{i}}{ }^{2}$ is the mean cross-sectional area at the transition and $t_{\mathrm{i}}$ is the age of the firn in years at the transition. The specific surface area calculated at the transition is that due solely to spherical bubbles; the value calculated for firn with $v=0.50$ is the crystal surface area; and therefore exceeds the true ice-air surface by including the grain-boundary area between touching grains. This over-estimate is probably compensated by the assumption that the crystals are spherical, and both facts contribute to the uncertainty of the real specific surface area (Table IV).

TAble IV. Crystal size and $\mathrm{CO}_{2}$ Content derived from polar cores

\begin{tabular}{|c|c|c|c|c|c|c|c|c|c|c|}
\hline Location & $\begin{array}{c}\text { Firn } \\
\text { temperature } \\
{ }^{\circ} \mathrm{C}\end{array}$ & $\begin{array}{c}\text { Elevation } \\
\mathrm{m}\end{array}$ & $\begin{array}{l}D_{0}^{2} \\
\mathrm{~mm}^{2}\end{array}$ & $\begin{array}{c}S_{0} \\
\mathrm{~m}^{2} \mathrm{~kg}^{-1}\end{array}$ & $\begin{array}{c}k \\
\mathrm{~mm}^{2} \text { year }^{-1}\end{array}$ & $\begin{array}{l}l_{1} \\
\text { year }\end{array}$ & $\begin{array}{l}D_{1^{2}} \\
\mathrm{~mm}^{2}\end{array}$ & $\begin{array}{c}S_{1} \\
\mathrm{~m}^{2} \mathrm{~kg}^{-1}\end{array}$ & $\begin{array}{c}\text { Excess } \mathrm{CO}_{2} \\
\text { molecules } \\
\mathrm{kg}^{-1}\end{array}$ & $\begin{array}{c}\text { monolayers, } \\
t=t_{1}\end{array}$ \\
\hline Plateau, Antarctica & -57 & 3624 & $0.4^{8}$ & $4 \cdot 7$ & 0.0007 & 3500 & 2.8 & 0.45 & & \\
\hline Inge Lehmann, Greenland & -30 & 2407 & 0.95 & $3 \cdot 3$ & 0.007 & 400 & 3.8 & $\begin{array}{l}0.39 \\
0.38\end{array}$ & & \\
\hline "Byrd" station, Antarctica & -28 & I 886 & 0.59 & 4.2 & $\begin{array}{l}0.012 \\
0.016\end{array}$ & 280 & $\begin{array}{l}4.0 \\
2.5\end{array}$ & $\begin{array}{l}0.3^{8} \\
0.4^{8}\end{array}$ & $8.8 \times 10^{18}$ & $\begin{array}{l}1.4 \\
3.7\end{array}$ \\
\hline "Camp Century", Greenland & -24 & I 510 & 0.55 & $4 \cdot 4$ & 0.016 & 125 & & & & $3 \cdot 7$ \\
\hline
\end{tabular}

We can see that the specific surface area changes from $c .300 \mathrm{~m}^{2} \mathrm{~kg}^{-1}$ in falling snow to around $4 \mathrm{~m}^{2} \mathrm{~kg}^{-1}$ at a few metres depth in a polar ice sheet, and to around $0.4 \mathrm{~m}^{2} \mathrm{~kg}^{-1}$ at the firn-ice transition. If specific surface area was the sole criterion in defining the strength of the dispersion of the ice then there should be dramatic reductions in the strength of the polarization and the conductivity both in the snow and in the ice component alone with increasing density.

Experiments on polar cores from "Mizuho", Antarctica, by Maeno (1974[a]) and from site 2, Greenland, by Paren (1973) demonstrate that the limiting high-frequency conductivity of the firn for ice-volume fractions $v$ greater than 0.66 is higher than that found in the deeper impermeable ice below. Glen and Paren (1975) have discussed this result, suspecting contamination. There is scatter in Maeno's data but the conductivity increases with increasing density until $v$ is 0.80 ; at higher densities the conductivity falls, but after $v$ has attained $0.9^{2}$ 


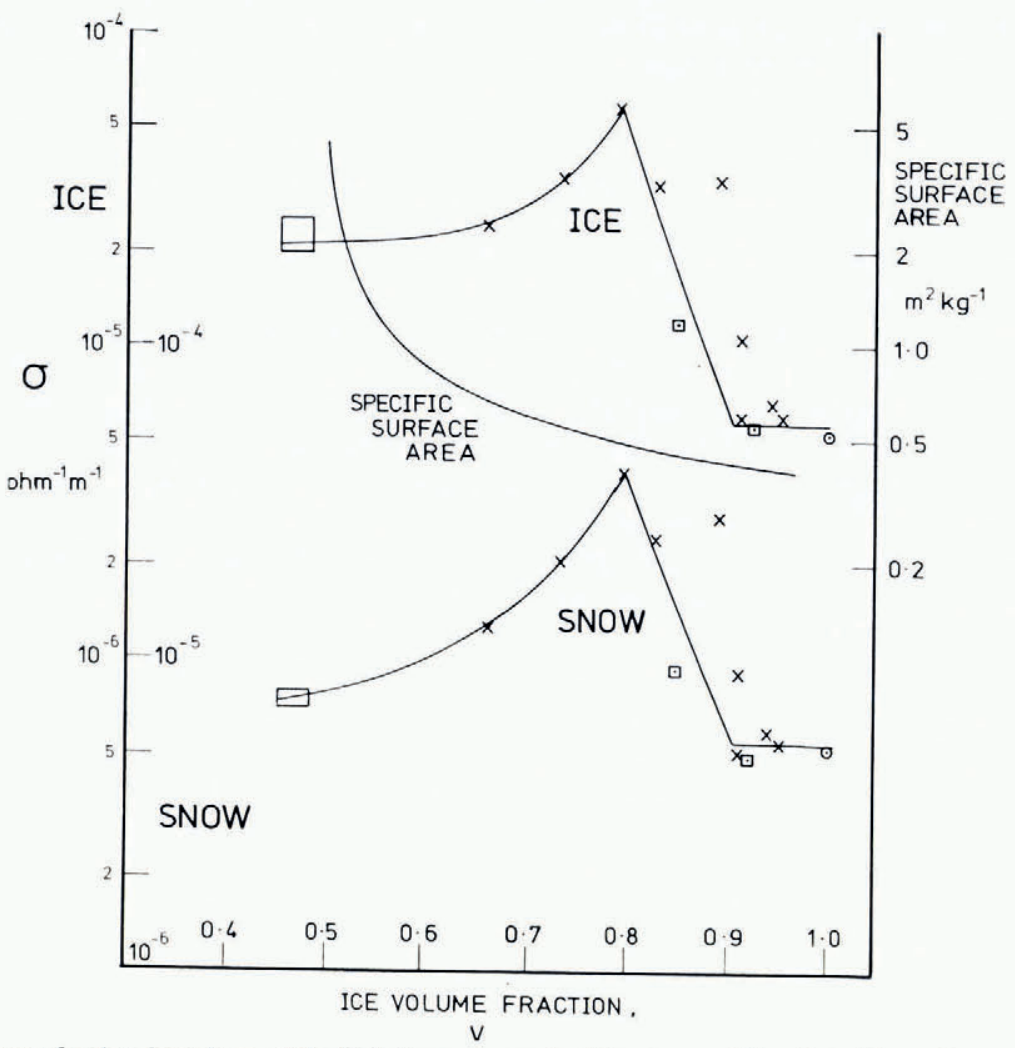

Fig. 8. The volume-fraction dependence of the high-frequency conductivity at $-45^{\circ} \mathrm{C}$ and specific surface area of polar firn. Data are $\left(\Delta \sigma_{1}+\Delta \sigma_{2}\right)$ for finely divided ice and deep "Byrd" station ice (○) from Table II, and high-frequency conductivity of firn from "Mizuho", Antarctica, by Maeno $(1974[a],[b])(\times)$ and of firn from site 2, Greenland, by Paren (1973) (-). The solid-component (ice) conductivity has been calculated from that of the snow or firn using equation (Io) of Glen and Paren (1975), which is a development of Looyenga's equation.

the conductivity of the solid phase (ice) is essentially unchanged. At all densities of firn and impermeable polar ice the activation energy for the limiting high-frequency conductivity is similar between 0.20 and $0.25 \mathrm{eV}$, and there is a smooth transition in behaviour between the firn and deep ice. Figure 8 shows the density dependence of snow conductivity and also that derived for the solid phase at $-45^{\circ} \mathrm{C}$. Data are from the finely-divided ice experiments discussed here, and from experiments on cores from "Mizuho" and "Byrd" station, Antarctica, and from site 2 in Greenland. Independent measurements on the behaviour of firn and compressed finely divided ice at higher densities are urgently required to verify elsewhere the behaviour observed at "Mizuho" by Maeno. A crude estimate of typical specific surface areas for the sites in Table IV is also given in Figure 8 to show the trends expected for the ice-phase conductivity solely from this influence.

\section{Adsorption of $\mathrm{CO}_{2}$ ON ICE: EVIDENCE AND POSSIBLE EFFEGTS}

The surface per se cannot be the reason for the change of electrical behaviour with increase in density. For, when any finely divided ice sample is prepared and compressed in air, the conductivity rises with time and stabilizes. Our experiments suggest this stabilization can take up to a week at $-7^{\circ} \mathrm{C}$. This occurs when the specific surface area becomes smaller. Rather this would seem to suggest an interaction of gas and the ice at or through the ice-air interface. 
We believe that the gas which is most likely to be of importance is carbon dioxide, since finely divided ice in contact with air is known to contain high $\mathrm{CO}_{2}$ levels, and we believe that the dielectric behaviour of the deep polar ice may be determined by the presence of this gas.

Alder and others ( 1969 ) demonstrated that the $\mathrm{CO}_{2}$ content of a Greenland ice sample was increased by a factor of $\mathrm{I}$ I on shaving the ice and creating a greater specific surface area. Such adsorbed $\mathrm{CO}_{2}$, according to Alder and others, remains even if the sample is transferred to an evacuated chamber, so that the adsorption is not reversible. Experiments to relate $\mathrm{CO}_{2}$ concentration to specific surface area in polar firn have not yet been performed. Even so, provided the firn has not changed to ice and the material is thus freely open to the atmosphere, we expect that as the density increases, the adsorbed $\mathrm{CO}_{2}$ level will fall, since the monolayer area decreases and gaseous exchanges can still occur. After the firn-ice transition, the $\mathrm{CO}_{2}$ content is frozen in, and as the specific surface area falls further the $\mathrm{CO}_{2}$ must re-distribute itself in the most energetically favourable way, either by diffusion into the ice or into the air. Measurements have been made of the concentrations of various gases in deep ice at "Byrd" station, Antarctica, and at "Camp Century", Greenland (Raynaud and Delmas, 1977). N 2 , $\mathrm{O}_{2}$, and $\mathrm{Ar}$ concentrations follow the same ratio as in the free atmosphere, but the $\mathrm{CO}_{2}$ concentration levels are enhanced by a mean factor of four at "Byrd" station and eleven at "Camp Century", and there is wide scatter in the $\mathrm{CO}_{2}$ levels from different depths of the cores. From a knowledge of the porosity, volume, temperature, and pressure conditions when the firn becomes ice, we can calculate the $\mathrm{CO}_{2}$ concentrations in the bubbles in the absence of adsorption assuming contemporary atmospheric composition. The number of excess $\mathrm{CO}_{2}$ molecules in the ice follows directly (Table IV). Adamson and Jones (I97I) estimated the area covered by a $\mathrm{CO}_{2}$ molecule when adsorbed as a monolayer on ice to be $20 . \mathrm{I} \times \mathrm{IO}^{-20} \mathrm{~m}^{2}$. The number of monolayers required to accommodate the excess $\mathrm{CO}_{2}$ may therefore be determined at the firn-ice transition using the values given in Table IV. The mean values are I.4 monolayers at "Byrd" station and 3.7 monolayers at "Camp Century" assuming a molecularly smooth surface; such calculations may therefore over-estimate the layer thickness. These figures suggest that at "Byrd" station a $\mathrm{CO}_{2}$ monolayer is associated with the bubbles at the firn-ice transition. Raynaud and Delmas suggested that the presence of carbonate impurities in the ice at "Camp Century" was the reason for the higher $\mathrm{CO}_{2}$ levels which they measured.

Experiments on deep polar ice cores and parameters derived from geophysical electrical surveying techniques have led to the conclusion that polar ice behaves as if it is impure by comparison with pure ice single crystals. The impurity responsible for this may be $\mathrm{CO}_{2}$. It is impossible for the impurity to be hydrofluoric acid but, by comparison with the dielectric behaviour of HF-doped monocrystals (Camplin and Glen, 1973) an HF concentration of $1.4 \times 1^{-7} \mathrm{~mol}$ fraction would reproduce the observed behaviour of the high-frequency conductivity and d.c. conductivity of deep "Camp Century" ice (Paren, I973), and the highfrequency conductivity of deep "Byrd" station ice. The range of observed in situ d.c. conductivities of polar ice (see Glen and Paren, 1975, fig. 4) can be accounted for by an HF concentration range of $\left(0.4^{-2.5}\right) \times \mathrm{rO}^{-7} \mathrm{~mol}$ fraction. These $\mathrm{HF}$ concentrations are in the range of the average excess $\mathrm{CO}_{2}$ calculated for deep ice at "Byrd" station and "Camp Century" of (o.8 and 2.7) $\times 10^{-7}$ mol fraction, respectively. $\mathrm{HF}$, by its substitution for water molecules in the ice lattice, generates in significant numbers extrinsic $\mathrm{H}_{3} \mathrm{O}^{+}$ions and Bjerrum $\mathrm{L}$ defects in the range of concentration and temperature of interest. Little is known of the mode of incorporation of $\mathrm{CO}_{2}$ in ice (except when in clathrate form) and no models have been presented on the bonding of the molecules to the lattice or of the possible defect reactions that may occur. Reactions in pure water are very well known. At $0^{\circ} \mathrm{C}, \mathrm{I} \times \mathrm{IO}^{-7}$ mol fraction of $\mathrm{CO}_{2}$ generates $2 \times \mathrm{IO}^{-8} \mathrm{~mol}$ fraction of $\mathrm{H}_{3} \mathrm{O}^{+}$ions, whereas at the same concentration $\mathrm{HF}$ is fully dissociated. This comparison suggests that $\mathrm{CO}_{2}$ should be less efficient in generating extrinsic electrical defects in ice than $\mathrm{HF}$, and higher concentrations of $\mathrm{CO}_{2}$ would be needed to "reproduce" the general effect of a given HF doping. 
$\mathrm{CO}_{2}$ monolayer formation should lead to similar $\mathrm{CO}_{2}$ levels in deep ice from different polar sites in the absence of localized melting, since the specific surface area at the firn-ice transition shows little variation between polar sites (Table IV). If it is correct to attribute the electrical behaviour of deep ice to the $\mathrm{CO}_{2}$, this would explain the reasons for the similar electrical behaviour at many different polar locations providing that the $\mathrm{CO}_{2}$ originating in the shrinking bubbles did in fact diffuse into the ice. At great depths the specific surface area becomes negligible as the bubbles disappear, when the air hydrate which includes the $\mathrm{CO}_{2}$ component becomes fully integrated into the ice lattice (Miller, r969).

It is of interest to compare our experiments on finely divided ice with experiments carried out on polar firn. Unfortunately, we did not measure the specific surface areas in the laboratory experiments, but our shaved ices have much in common with those prepared by Alder and others (I969), who demonstrated the eleven-fold enhancement of the $\mathrm{CO}_{2}$ concentration after "finely shaving" Greenland ice in air at $-12^{\circ} \mathrm{C}$. Weiss and others (1972) have calculated the S.T.P. $\mathrm{CO}_{2}$ content of the shaved samples to be $0.86 \mathrm{ml} \mathrm{kg}^{-1}$. If the $\mathrm{CO}_{2}$ were assumed to exist as a single monolayer on the ice surfaces, we can calculate the necessary surface area; it is $4.6 \mathrm{~m}^{2} \mathrm{~kg}^{-1}$. Such a surface area is very representative of the $S_{0}$ values obtained in polar firn near the surface (Table IV). Thus in the spirit of this analysis, it is possible that our finely divided ice represents not only the required density range for surface firn but also its surface area.

We have suggested that $\mathrm{CO}_{2}$ controls the electrical properties of laboratory and polar ice. It is important that our hypothesis can also explain the in situ differences between temperate and polar glacier ice. There is no doubt that differences exist; four-electrode d.c. resistivity measurements have led to d.c. conductivities of $c \cdot 10^{-5} \Omega^{-1} \mathrm{~m}^{-1}$ for deep polar ice and much lower values for temperate ice with an observed trend for lower conductivities towards temperate glacier snouts where values as low as $6 \times 10^{-9} \Omega^{-1} \mathrm{~m}^{-1}$ are found. However, the surface layers of both snow-covered temperate glaciers and polar glaciers have a conductivity in the range $(\mathrm{I}-4) \times \mathrm{IO}^{-6} \Omega^{-1} \mathrm{~m}^{-1}$. The indication is clear; the snows which fall in both temperate and polar regions have similar electrical properties, at least as far as d.c. measurements are concerned. But as time goes on and firnification processes take their course, the ice in the temperate glacier becomes apparently purer, whereas the ice in the polar glacier becomes more impure, although such changes can be ascribed to changes in the density and changes in the geometry of the grain bonding. We emphasize that these geometry changes occur in both polar and temperate ice, but that marked differences occur after firnification has taken place.

Table $\mathrm{V}$ shows a summary of the $\mathrm{CO}_{2}$ levels in polar and temperate ice. There are not the striking differences in $\mathrm{CO}_{2}$ level which one might expect to find between polar and temperate ice. Values of $\mathrm{CO}_{2}$ levels for shaved Greenland ice and the Jungfraujoch are similar, as are those for the deep "Byrd" station, the deep "Camp Century" and Grosser Aletschgletscher snout.

These values do not lend support to the simple $\mathrm{CO}_{2}$ control that we have envisaged unless the dissolution of $\mathrm{CO}_{2}$ into the ice matrix in temperate glaciers occurs by a different mechanism from that which operates in polar glaciers. Temperate glacier ice is always in intimate contact with liquid water and, it is believed, as recrystallization takes place, the ice is constantly

TABle V. $\mathrm{CO}_{2}$ Levels IN POLAR AND Temperate glacier ice

\section{Location}

Jungfraujoch

Grosser Aletschgletscher snout

Shaved Greenland ice

Excess : deep "Byrd" station

Excess: deep "Camp Century"

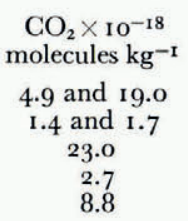

8.8

\section{Reference}

Weiss and others (1972)

Weiss and others (1972)

Weiss and others (1972)

Table IV

Table IV 
being swept free of impurities by the vein system in the glacier (Glen and others, 1977). The $\mathrm{CO}_{2}$ will exist primarily as $\mathrm{H}_{2} \mathrm{CO}_{3}$ or $\mathrm{HCO}_{3}-$ ions in the temperate glacier and is more likely to be found in the vein system.

Polar ice from a dry-snow zone, on the other hand, is never in contact with liquid water and the atmospheric $\mathrm{CO}_{2}$, which is at first contained in bubbles, and monolayers will, under the overburden pressure, eventually dissolve in the solid ice possibly in clathrate form. Even though the $\mathrm{CO}_{2}$ will revert to a non-clathrate form when ice is returned to the surface during drilling operations, it is never in contact with liquid water and so cannot be removed from the ice by dissolving in water.

\section{Conclusions}

We have discussed at length the possible origin of the enhanced dielectric relaxation rate and conductivity in finely divided ice, snow, firn, and polar ice. Crucial to the discussion is the result of five simple experiments on finely divided ice prepared in air using a cheese grater, and compressed to higher density.

Many of the ideas expressed can be put to the test in future experiments. For instance, the influence of $\mathrm{CO}_{2}$ should be investigated by growing the ice and preparing the finely divided samples under an argon atmosphere. The influence of crystal size, specific surface area, density, and temperature of preparation and storage should be investigated, since they all play a role in the ageing and eventual stable behaviour of the samples. Further experiments should be undertaken on cores of polar firn from cold locations like "Mizuho" (where the mean annual temperature is around $-33^{\circ} \mathrm{C}$ ) to see if the unexpected results in Figure 8 are due in part to ageing processes which are slow at low in situ temperatures. Measurements are needed of specific surface area and of $\mathrm{CO}_{2}$ levels in ice, snow, and firn, to explore the extent to which the present scatter in $\mathrm{CO}_{2}$ data is due to experimental uncertainties. Above all, electrical studies should be undertaken on monocrystals of ice containing carbonic acid and on finelydivided doped ice.

\section{Acknowledgements}

This research was supported by a research grant from the Natural Environment Research Council. J.G.P. would like to thank the British Antarctic Survey for the freedom to complete this work in the course of investigations on the polar firn of Antarctica. We should like to thank Dr D. A. Peel for discussions on carbon dioxide.

\section{REFERENCES}

Adamson, A. W., and Jones, B. R. 1971. Physical adsorption of vapors on ice. IV. Carbon dioxide. Fournal of Colloid and Interface Science, Vol. 37 , No. 4, p. $831-35$.

Adamson, A. W., and others. 1967. Physical adsorption of vapors on ice. I. Nitrogen, [by] A. W. Adamson, L. M. Dormant and M. J. Orem. Fournal of Colloid and Interface Science, Vol. 25, No. 2, p. $206-17$.

Addison, J. R. r 970 . Electrical relaxation in saline ice. Fournal of Applied Physics, Vol. 41, No. I, p. 54-63.

Alder, B., and others. 1969. Gas composition in ice samples collected by E.G.I.G. in Greenland, by B. Alder, J. Geiss, N. Groegler and A. Renaud. Meddelelser om Gronland, Bd. 177, Nr. 2, p. 10o-07.

Beek, L. K. H. van. 1967. Dielectric behaviour of heterogeneous systems. Progress in Dielectrics, Vol. 7, p. 69-1 14.

Camplin, G. C., and Glen, J. W. 1973. The dielectric properties of HF-doped single crystals of ice. (In Whalley, E., and others, ed. Physics and chemistry of ice: papers presented at the Symposium on the Physics and Chemistry of Ice, held in Ottawa, Canada, I4-18 August 1972. Edited by E. Whalley, S. F. Fones, L. W. Gold. Ottawa, Royal Society of Canada, p. $256-6$ i.)

Fitzgerald, W. J., and Paren, J. G. 1975. The dielectric properties of Antarctic ice. Fournal of Glaciology, Vol. I 5 , No. 73 , p. $39^{-48 .}$

Fitzgerald, W. J., and others. 1977. Are the anomalous dielectric properties of polar ice due to impurities? By W. J. Fitzgerald, J. W. Glen and J. G. Paren. [Union Géodésique et Géophysique Internationale. Association Internationale des Sciences Hydrologiques. Commission des Neiges et Glaces.] Symposium. Isotopes et impuretés dans les neiges et glaces. Actes du colloque de Grenoble, août/septembre 1975, p. 3-8. (IAHS-AISH Publication No. 1 18.$)$ 
Fujino, K. 1967. Kaihyō no yūdenteki seishitsu ni kansuru kenkyū [Dielectric properties of sea ice]. Teionkagaku: Low Temperature Science, Ser. A, [No.] 25, p. 127-69.

Glen, J. W., and Paren, J. G. 1975. The electrical properties of snow and ice. Fournal of Glaciology, Vol. I 5, No. 73,
p. I 5-38.

Glen, J. W., and others. 1977. Water at grain boundaries: its role in the purification of temperate glacier ice, by J. W. Glen, D. R. Homer and J. G. Paren. [Union Géodésique et Géophysique Internationale. Association Internationale des Sciences Hydrologiques. Commission des Neiges et Glaces.] Symposium. Isotopes et impuretés dans les neiges et glaces. Actes du colloque de Grenoble, aout/septembre 1975, p. 263-7I. (IAHS-AISH Publication No. I 18. )

Gough, S. R., and others. 1974. Dielectric properties of some clathrate hydrates of structure II, by S. R. Gough, R. E. Hawkins, B. Morris and D. W. Davidson. Journal of Physical Chemistry, Vol. 77, No. 25, p. 2969-76.

Gow, A. J. 1971. Depth-time-temperature relationships of ice crystal growth in polar glaciers. U.S. Cold Regions Research and Engineering Laboratory. Research Report 300.

Loor, G. P. de. Unpublished. Dielectric properties of heterogeneous mixtures. [Ph.D. thesis, Rijksuniversiteit te Leiden, 1956.]

Maeno, N. I $974[\mathrm{a}]$. Investigations of electrical properties of deep ice cores obtained by drilling in Antarctica. (In Kyokuchihyō shōhyō no butsuriteki kagakuteki kenkyū [Physical and chemical studies on ices [sic] from glaciers and ice sheets]. Monbushō Kagaku Kenpi Sōgō Kenkyzu (A). Hokokusho, [1973], p. 45-56.)

Maeno, N. I974[b]. Kyokuchi no kōri no denkiteki-seishistu. I [Electrical properties of polar ice. I]. Teionkagaku: Low Temperature Science, Ser. A, [No.] 32, p. 25-38.

Miller, S. L. 1969. Clathrate hydrates of air in Antarctic ice. Science, Vol. 165, No. 3892, p. 489-9o.

Paren, J. G. 1973. The electrical behavior of polar glaciers. (In Whalley, E., and others, ed. Physics and chemistry of ice: papers presented at the Symposium on the Physics and Chemistry of Ice, held in Ottawa, Canada, $14-18$ August 1972. Edited by E. Whalley, S. F. Fones, L. W. Gold. Ottawa, Royal Society of Canada, p. 262-67.) Polder, D., and Santen, J. H. van. 1946. The effective permeability of mixtures of solids. Physica, Vol. 12, No. 5 ,
p. $257^{-71}$.

Raynaud, D., and Delmas, R. 1977. Composition des gaz contenus dans la glace polaire. [Union Géodésique et Géophysique Internationale. Association Internationale des Sciences Hydrologiques. Commission des Neiges et Glaces.] Symposium. Isotopes et impuretés dans les neiges et glaces. Actes du colloque de Grenoble, août/septembre 1975, p. 377-8 1 .
(IAHS-AISH Publication No. 1 I 8.)

Von Hippel, A. R., and others. 1972 . Dielectric and mechanical response of ice $\mathrm{I}_{\mathrm{h}}$ single crystals and its interpretation, by A. [R.] Von Hippel, R. Mykolajewycz, A. H. Runck and W. B. Westphal. Journal of Chemical Physics,
Vol. 57, No. 6, p. 2560-7I.

Weiss, R. F., and others. 1972. Compositional variations of gases in temperate glaciers, [by] R. F. Weiss, P. Bucher, H. Oeschger and H. Craig. Earth and Planetary Science Letters, Vol. 16, No. 2, p. 178-84.

\section{DISGUSSION}

B. Stauffer: Why did you do your experiments at a density of around $0.4 \mathrm{Mg} \mathrm{m}^{-3}$ rather than at densities above the critical density of $0.56 \mathrm{Mg} \mathrm{m}^{-3}$ which would be more representative of firn in nature? Why did you carry out your ageing experiments only at $-7^{\circ} \mathrm{C}$ ? Surely there is the danger of a great influence from a water-like layer around the ice grains.

J. G. PAREN: Our experiments on compressed finely divided ice were performed to compare with similar experiments on snow of density $0.3^{8} \mathrm{Mg} \mathrm{m}^{-3}$ undertaken by Fujino, and to compare with some field observations I made in Arctic Canada and subsequent experiments on the plateau of the Antarctic Peninsula. Field experiments I have conducted have been on firn generally within $2 \mathrm{~m}$ of the surface and in situ densities have been in the range $0.3^{8-0.50}$ $\mathrm{Mg} \mathrm{m}^{-3}$. We now know how much scatter there is for a fairly narrow density range and we would hope that further experiments could investigate the properties of more dense firn, especially after the "critical packing" density of $0.56 \mathrm{Mg} \mathrm{m}^{-3}$ is exceeded.

Ageing experiments were conducted at $-7^{\circ} \mathrm{C}$ to ensure the most rapid ageing within feasible time limits. By comparison with the rate of ageing at $-7^{\circ} \mathrm{C}$, the ageing process was effectively stopped at a temperature of $-\mathrm{I} 7^{\circ} \mathrm{C}$. I do not know the extent to which the waterlike layer on ice surfaces influences the rate of ageing and the stable behaviour which eventually results. Previous experiments by the groups at Pau in France on the ageing of micro-crystals of ice have been interpreted strictly in terms of the temperature of preservation.

P. CAmP: Is there any possibility that the similarity between your results on finely divided ice and those for Antarctic ice is a consequence of the gas trapped in the Antarctic ice being dispersed in sub-microscopic bubbles, thereby creating a rather large internal surface area? 
Paren: Yes, it is possible but we prefer our interpretation for the following reasons. In situ d.c. experiments on deep polar ice do give conductivity values that are consistent within a factor of two with those measured on cores retrieved from great depth. In the former case, the in situ air is in clathrate form or in sub-microscopic bubbles; in the latter case, small bubbles are found but these have been seen to appear during the pressure release immediately after drilling. The gas content of the two sets of samples could in principle be identical. As regards dielectric properties, there is again a good correspondence between the inferred dielectric absorption in the $\mathrm{MHz}$ frequency band in polar ice in situ and measurements taken on retrieved and depressurized cores. The data of Figure 8 are all taken on retrieved cores and there is a lack of any major density dependence above $V=0.90$ where the conductivity levels exceed those of pure monocrystals of ice. This can be interpreted either in terms of a constant gaseous or soluble impurity concentration or a constant specific surface area. We believe, on balance, that the former explanation is more likely, since the densities associated with the points were measured on the retrieved cores and should reflect changes in the specific surface area.

C. JACGARD: Do you observe an anomalous temperature dependence near the melting point, indicating an effect of a quasi-liquid surface layer?

PAREN: We have not investigated in any real detail the temperature dependence of the dielectric relaxation near the melting point in finely divided ice. A detailed investigation for deep polar ice appeared in my paper in the Ottawa symposium volume.

The d.c. conductivities derived from a.c. measurements for our samples did provide evidence for an anomalous temperature dependence near the melting point. Our measurements agree very well with those under static fields by Kopp (1962) for fresh snow from the Weissfluhjoch compressed to higher densities. In particular, the activation energy is $(0.70 \pm 0.0 \mathrm{I}) \mathrm{eV}$ and the conductivity at $-40^{\circ} \mathrm{C}$ is typically $6 \times 1 \mathrm{o}^{-9} \Omega^{-1} \mathrm{~m}^{-1}$. Above $-10^{\circ} \mathrm{C}$ the activation energy is higher as Kopp also found. A value of $1.4 \mathrm{eV}$ is typical for our samples and corresponds to that found for the surface conductivity of mono-crystals.

W. R. Bloch: Could $\mathrm{CO}_{2}$ and other gases have been moved to great depth by liquid water (in very low-temperature ice) according to the Weertman mechanism?

PAREN: As long as water and ice co-exist in thermodynamic equilibrium in a glacier and the liquid veins are able to sweep through the ice during deformation, there should be a preferential removal from the ice component of gases that are more soluble in water. Even if the veins are not intercommunicating and hence there is no net flow of water, there will still be a separation of impurities from the grains to the liquid network. One question at issue is: given the grain geometry, temperature, stress field, and impurity level of cold ice, is there a significant enough quantity of water to ensure purification within a reasonable time? I must certainly study the papers on the Weertman mechanism to see the implication of your question for water flow in larger channels than the vein system.

C. Hammer: Could your conductivity changes with depth of polar ice be explained by acids rather than by $\mathrm{CO}_{2}$ content. I should comment that recent data I have collected from Greenland show that polar ice may be heavily doped by volcanic acids.

Paren: To me, the work you have recently described is most exciting, showing high d.c. conductivity levels in polar ice cores known to have been deposited at times of volcanic activity. The question concerns the origin of the background level of d.c. conductivity (and other dielectric parameters) upon which the "volcanic peaks" are superimposed.

There is no proof that any one impurity is responsible. The major problem has been to find an impurity available in sufficient quantity to account for an observed behaviour which 
appears rather uniform and similar in Greenland and Antarctic ice in locations where impurity levels of sea salts and condensation nuclei are variable and in certain cases extremely low. I note that, according to the tabulations of Federer (1970), and Lorius and others (1969), the mean sulphate concentrations for Greenland and Antarctica are both similar-around $2 \mathrm{IO} \mu \mathrm{g} / \mathrm{l}$ in Greenland and $250 \mu \mathrm{g} / \mathrm{l}$ in the inland ice of Antarctica, corresponding to $4 \times 1 \mathrm{IO}^{-8}$ mol fraction, whereas the average measurements for $\mathrm{CO}_{2}$ in deep ice at "Byrd"' station and "Camp Century" are $\mathrm{I} . \mathrm{I} \times \mathrm{IO}^{-7}$ and $3.0 \times \mathrm{IO}^{-7} \mathrm{~mol}$ fraction, respectively. If sulphate ions are responsible for the "background" values of dielectric parameters, I wonder whether there is a corresponding adsorption of sulphates by ice surfaces to account for the experimental values in Greenland and Antarctica, and to account for the results I obtained by finely dividing ice. I must admit the sulphate ion seems a good candidate. Perhaps measurements should be undertaken on ice containing the natural aerosol of ammonium sulphate?

\section{REFERENGES} Federer, B. I970. Neutron activation determination of the aerosol content of Greenland snow. Pure and Applied
Geophysics, Vol. 79, No. 1970/II, p. 1 20-27. Kopp, M. I962. Conductivité électrique de la neige, au courant continu. Zeitschrift für angewandte Mathematik
und Physik, Bd. I3, Ht. 5, p. 431-4I.

Lorius, C., and others. 1969 . Impuretés solubles contenues dans la glace de l'Antarctique, [par] C. Lorius, G. Baudin, J. Cittanova [et] R. Platzer. Tellus, Vol. 2 I, No. I, p. ${ }_{136-48 .}$ 